\title{
Recent advances in enzyme promiscuity
}

\author{
Rinkoo Devi Gupta*
}

\begin{abstract}
Enzyme promiscuity is defined as the capability of an enzyme to catalyze a reaction other than the reaction for which it has been specialized. Although, enzyme is known for its specificity, many enzymes are reported to be promiscuous in nature. However, the promiscuous function may not be relevant in physiological conditions. The reasons could be either very low level of catalytic activity or unavailability of the substrates in the cell. Hitherto, the enzyme promiscuity is of great importance because they are the starting point for the evolution of new functions in the nature. In addition, the promiscuous activities are utilized for the development of new catalytic functions by applying directed laboratory evolution and protein engineering techniques. The aim of this review is to provide recent developments on the understanding of the mechanism of catalytic promiscuity, evolvability of promiscuous functions and the applications of enzyme promiscuity in the designing of enhanced or new functional biocatalysts.
\end{abstract}

Keywords: Enzyme promiscuity, Directed evolution, Protein evolution

\section{Background}

Enzymes are well known for catalyzing specific reactions and hence the specificity is a key feature of enzymes. However, there are many exceptions of this universally accepted enzyme specificity, which have been intensive area of research since last two decades. These enzymes are capable of binding with more than one substrates and catalyzing reactions other than its physiological substrate. The secondary function of enzyme is referred as promiscuous function, moonlighting function, substrate ambiguity or some time as cross reactivity of enzymes [1, 2]. Generally, enzymes catalyze a range of similar substrates of the same class by identical reaction mechanism, which is referred as broad substrate specificity. Hence, commonly occurring broad substrate specificity, for example lipase catalyzes a broad range of carboxylic acids and alcohols, are not considered as enzyme promiscuity. However, it also catalyzes $\mathrm{C}-\mathrm{C}$ bond formation reactions, which is a promiscuous function of lipase. Other examples are Glutathione $\mathrm{S}$ transferase, cytochrome $\mathrm{P} 450$ and serum paraoxonase, which are known to neutralize a broad range of related substrates, are not promiscuous

*Correspondence: rdgupta@sau.ac.in; rinkoodgupta@gmail.com Faculty of Life Sciences and Biotechnology, South Asian University, New Delhi 110021, India functions. However, they also catalyze dissimilar substrates that are promiscuous functions of these enzymes. For better distinction between promiscuous function and broad substrate specificity, the function of enzyme, which has no physiological relevance, can be categorized as promiscuous function.

If not all, several enzymes are promiscuous in nature. The physiologically irrelevant promiscuous function of an enzyme is hypothesized to be the starting point for the evolution of new enzymes [1]. This hypothesis was proven by the excellently designed experiments in the laboratory by applying directed laboratory evolution technique on the targets like serum paraoxonase, bacterial phosphotriesterase and several other enzymes [3-6]. Subsequently, many other promiscuous enzymes were studied for the evolution of new enzymes [7, 8], and to appreciate the mechanistic and evolutionary prospective $[1,2,9-11]$. Previous reviews highlight the importance of promiscuity, and also examined the possible mechanisms $[1,6,12]$. Other more recent reviews have focused on the practical implications of enzyme promiscuity in the development of biocatalysts involved in organic synthesis [13-15], or divergence in certain enzyme families [1619]. The aim of writing this review is to encapsulate the advances in the field of enzyme promiscuity. Focus of the review is to highlight the recent findings on mechanism

\section{Springer}

C 2016 Gupta. This article is distributed under the terms of the Creative Commons Attribution 4.0 International License (http:// creativecommons.org/licenses/by/4.0/, which permits unrestricted use, distribution, and reproduction in any medium, provided you give appropriate credit to the original author(s) and the source, provide a link to the Creative Commons license, and indicate if changes were made. The Creative Commons Public Domain Dedication waiver (http://creativecommons.org/publicdomain/ zero/1.0/) applies to the data made available in this article, unless otherwise stated. 
of catalytic promiscuity, evolutionary potential of promiscuous functions and applications of enzyme promiscuity in the designing of novel biocatalysts.

\section{Mechanism of catalytic promiscuity}

Promiscuous nature of enzymes raises many questions in our mind for e.g., what makes an enzyme promiscuous? How does an active site of enzyme accommodate a substrate other than its physiological one? Previous studies showed that the mechanism of catalysis of promiscuous substrate is different from the physiological reaction mechanism. These mechanisms underlying enzyme promiscuity are based on the conformational diversity of enzyme's active site, substrate ambiguity, different protonation states, different subsites within the same active sites and cofactor ambiguity $[1,2]$. In my view, it can be categorized in three major groups based on the different factors responsible for enzyme promiscuity: (1) active site plasticity of enzymes, (2) substrate ambiguity and (3) cofactor ambiguity (Fig. 1) which have been deliberated below.

\section{Active site plasticity}

Active site plasticity of enzymes facilitates the binding with promiscuous substrates and thereby the catalysis. The plasticity allows enzyme active site to accommodate promiscuous substrate and thus the enzyme-substrate complex acquires diverse conformations. Hence, the native and the promiscuous functions are facilitated by different active-site conformations. For examples, $\beta$-lactamase and sulfo-transferase display increased

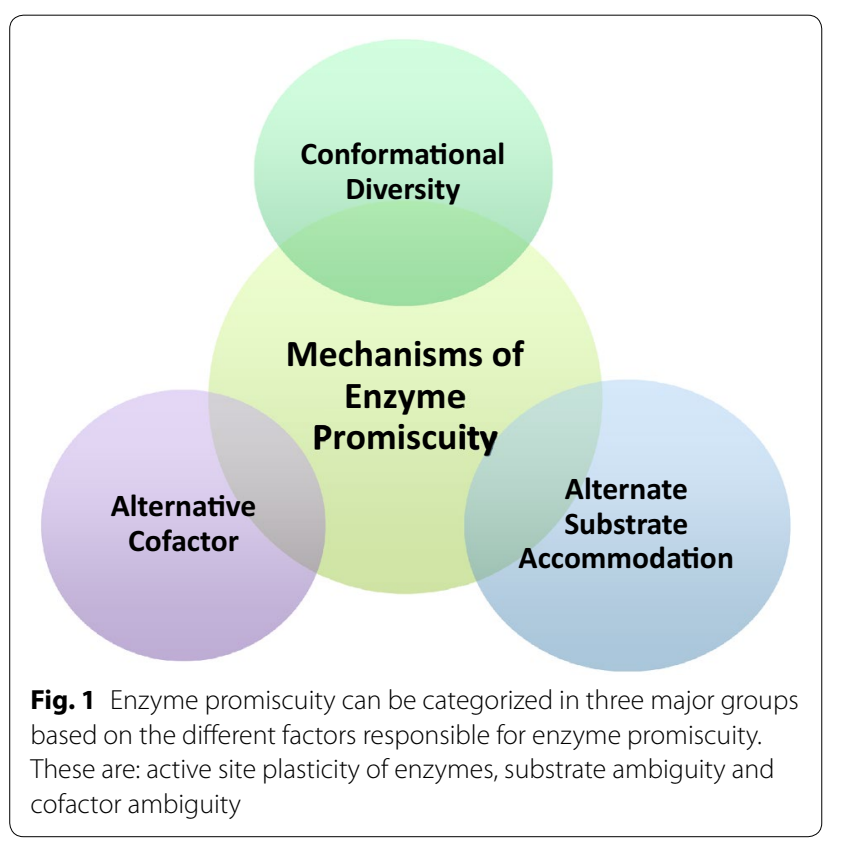

plasticity and altered substrate hydrolysis [20,21]. Other than active-site plasticity, many enzymes possess a loop like structure passing through or over the active site of enzyme, which determines the specificity [22, 23]. For example, isopropylmalate isomerase exhibits dual-substrate specificity, where the conformation of a loop differs on the specific substrate present [24]. In the above-mentioned examples as well as many other promiscuous enzymes, both the native and promiscuous activities reside within the same active site. However, there are evidences of different sub-sites within the same active site of enzymes. For example serum paraoxonase has native lactonase with promiscuous phosphotriesterase activity where hydrolysis of lactone is mediated by histidine dyad while phosphotriesterse activity is mediated by another set of residues in the same active site groove [1, 3] (Fig. 2).

\section{Ambiguous substrate}

Several enzymes can accommodate ambiguous substrates by different modes of interactions in the very same active site. Some of these might be employed by promiscuous substrates. For example, cytochromes P450 (CYP) represents a diverse group of heme-thiolate proteins, which share common protein fold however they differ in substrate selectivity. The mechanism of catalysis is through activation of molecular oxygen on varied monooxygenation reactions. Cytochrome CYP3A4 shows remarkably extreme promiscuity in substrate specificity and cooperative substrate binding. Sevrioukova has reviewed extensively the promiscuous nature of cytochromes P450 [25]. Similarly, salicylic acid binding protein has promiscuous esterase activity towards a series of substrates. The highest activity was reported for its native substrate, methyl salicylate that is mediated by substrate-assisted catalysis involving the hydroxyl group from methyl salicylic acid [26].

\section{Cofactor ambiguity}

In many enzymes, changes in cofactor alter enzyme specificity. Active sites of metalloenzymes harbor such amino acid side chain ligands, which create metal binding sites, are often capable of binding a range of metals and other chemical ligands. The binding of a variety of metals may create metal-binding promiscuity and thus catalytic promiscuity $[27,28]$. Metal-binding promiscuity can be employed in artificial metalloenzyme design by using the native scaffold [29]. Similarly, farnesyl diphosphate synthase, a key enzyme of isoprenoid biosynthetic pathway, displays its activity in the presence of metal cofactors. $\mathrm{Mg}^{2+}$ ions lead to the production of farnesyl diphosphate while the presence of $\mathrm{Co}^{2+}$ ions lead to geranyl diphosphate production. This metal ion-dependent enzyme promiscuity dictates a regulatory mechanism which 

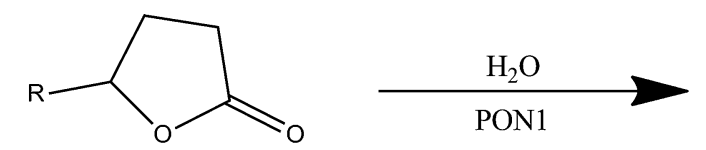

Lactone<smiles>[R]OP([R])(=O)Oc1ccc([N+](=O)[O-])cc1</smiles>

Paraoxon

Fig. 2 The native lactonase activity (with lactone substrate) and promiscuous phosphotriesterase activity (with paraoxon) catalyzed by serum paraoxonase (PON1)

allows a single enzyme to specifically control the metabolites it produces, thus potentially changing the flow of carbon into different metabolic pathways [30]. A recently identified enzyme named NDM-1, from Klebsiella pneumoniae from a patient sample, exemplifies extreme enzyme promiscuity. NDM-1 hydrolyzes and degrades nearly all known $\beta$-lactam-based antibiotics. NDM- 1 can employ different metal cofactors and different reaction mechanism for its promiscuous activities [31].

\section{Evolutionary potential of promiscuous function}

Many scientists have explored the evolutionary aspect of promiscuity $[1,2,32,33]$. It is proposed that a new function can evolve without negative trade-offs in the native activity, leading to a generalist enzyme. Later on, this generalist enzyme can become a specialist for a new catalytic activity. It is well stated that the process of natural evolution is gradual and slow. Owing to the weaker promiscuous activity as compare to native activity, it could be a better starting point for the evolution of new function. It also provides an immediate advantage to the gene under selection for a new function. Initially, weaker promiscuous activity can be compensated by higher expression level of the protein. Further, gradual improvement in the weaker promiscuous activities is achievable by accumulation of a few beneficial mutations or neutral mutations $[34,35]$. Small variations in the active site can lead to the emergence of new functions in existing protein folds. For evidence, bacterial and mammalian 6-pyruvoyltetrahydropterin synthase homologs catalyze distinct reactions using the same 7, 8-dihydroneopterin triphosphate as substrate. The bacterial enzyme catalyzes the formation of 6-carboxy-5, 6, 7, 8-tetrahydropterin, whereas the mammalian enzyme converts 7,8-dihydroneopterin triphosphate to 6-pyruvoyltetrahydropterin [36], which indicates that small variation in active site can lead to the emergence of new enzyme. This hypothesis has been utilized for the construction of an efficient and thermostable phosphotriesterase from lactonase by creating simple double mutations His250Ile and Ile263Trp [37].

When complicated and challenging enzyme activities are sought by applying directed evolution, smart gene libraries are required. A neutral drift of the gene can help in achieving such libraries. Neutral drift is a gradual accumulation of mutations under selection to maintain a protein's original function and structure, where each and every variant is folded and functional and maintains a certain degree of the enzyme's existing function. For making neutral libraries, several iterative rounds of mutagenesis and selection are applied to maintain the protein's original function and structure [34, 35]. This results a library of highly diversified mutants with different polymorphic characteristics. The most significant point regarding neutral libraries is that all the mutants are stable and functional which may not be available in the wild-type starting point. We have described the generation of neutral libraries for directed enzyme evolution using serum paraoxonase (PON1) as a model. This allowed the selection of mutants presenting improved activity, as well as the identification of mutants displaying higher specific activity. The resulting neutral libraries confined to only a few hundreds of variants. These neutral mutants were used as starting point for the directed evolution, which was resulted in array of new variants, including PON1 variants capable of degrading V-type organophosphates and sterically hindered organophosphates. This method is generally applicable methods for the preparation of such libraries starting from the wildtype gene $[34,35]$.

Neutral drift happening over billions of year results in considerable sequence divergence among proteins that binds with same molecule or catalyze the same reaction. 
Natural selection maintains the primary activity of these proteins; thereby maintain physiologically irrelevant promiscuous activities. Thus, the levels and the evolvability of promiscuous activities may vary among these orthologous proteins. For example, there are nine gammaglutamyl phosphate reductase (ProA) orthologs, which display different level of promiscuity varying by about 50-fold [38]. A single amino acid change from glutamine to alanine near the active site seemed to be critical for enhanced promiscuous activity in these orthologous genes. The improvement in the promiscuous activity has been shown wide-ranging from 50 - to 770 -fold. This fold improvement was not correlated with the original level of the promiscuous activity. Similarly, the decrease in the native activity varied from 190 - to 2100 -fold [38]. These results suggest that evolution of a novel enzyme may be possible with some orthologous enzymes, but not with all $[39,40]$. Hence, it is suggested to use several orthologous enzymes, instead of only one, as a starting point for directed laboratory evolution.

\section{Applications of promiscuous functions}

As we have discussed above, the promiscuity of enzymes can be a starting point for the divergent evolution. The low promiscuous activity towards a physiologically irrelevant substrate might turn the enzyme into a much more proficient catalyst which is possible by accumulation of just one or more beneficial mutations affording a survival benefit to the organism. Furthermore, a promiscuous function can be the starting point for the creation of a new enzyme activity by applying rational, semirational protein engineering methodologies or by applying directed laboratory evolution [41, 42]. Certain recent reports are discussed below where significant improvements in promiscuous activities and/or change in substrate specificity have been established (Table 1).

Organophosphates (OPs) poisoning poses great danger to both military and civilian populations. A timely and effective control with pharmacological agents can minimize the damage. Rapid in vivo organophosphate clearance requires bio-scavenging enzymes with catalytic efficiencies of more than $10^{7} \mathrm{M}^{-1} \mathrm{~min}^{-1}$. Hydrolysis of OPs by mammalian enzymes at high efficiency has been a challenge, specially the more toxic stereoisomer $S p$, with a required catalytic efficiency. Though mammalian PON1 is a foremost candidate for such a treatment, it hydrolyzes the toxic $S p$ isomers of G-agents with very slow rates. By performing three rounds of directed evolution of PON1, a new mutant for $S p$ isomer with a catalytic efficiency of the order of $10^{5} \mathrm{M}^{-1} \mathrm{~min}^{-1}$, which was $\sim 86,000$ fold improved over wild-type PON1 G3C9 was isolated (Fig. 3) [3]. Based on the mutations appeared in the variants obtained by directed evolution experiment and PON1's active sites, we designed a library by incorporating synthetic oligonucleotides via gene reassembly. Following shuffling of the improved variants, a screening of the random mutagenesis library resulted in a range of variants with the catalytic efficiency of up to $10^{7}$ $\mathrm{M}^{-1} \mathrm{~min}^{-1}$. We characterized several such mutants with broader stereo-specificity and also with different leaving groups, which could be used for the in vivo detoxification of real nerve agents. These in vivo prophylactic activity of evolved variants and the newly developed screens provide the foundation for designing PON1 and other OP degrading enzymes for prophylaxis against other G-type agents [3, 43].

Another category of nerve agent is V-type (VX and VR), which is known to be one of the most toxic substances. Promiscuous bacterial phosphotriesterases (PTEs) are capable of hydrolyzing VX but with very low level of activity [44]. PTE mutant library was created by mutating 12 active-site residues of PTE in order to enhance its catalytic efficiency. The library was screened for catalytic activity against a new VX analogue, DEVX, which contains the same thiolate-leaving group of $\mathrm{VX}$ attached to a diethoxyphosphate center rather than the ethoxymethylphosphonate center of VX. The evolved mutants showed up to 26-fold enhanced catalytic activity with DEVX relative to wild-type PTE. For further improvement, loop7 of Mutant PTE was mutated by error-prone PCR, which resulted in up to 78-fold increase in the rate of DEVX hydrolysis and 230-fold improvement in hydrolyzing racemic nerve agent VX as compare to wild-type wildtype PTE. However, stereo-selectivity for the hydrolysis of the two enantiomers of VX was relatively low [44]. The catalytic activity of PTE from A. radiobacter, for the common organophosphorous insecticide malathion was enhanced by changing serine to leucine at position 308 and tyrosine to alanine at position 309 , which resulted in 5000 -fold increase in $\mathrm{Kcat} / \mathrm{Km}$ value. X-ray crystal structures for the above variant demonstrate that the access to the binding pocket was enhanced by the replacement of the bulky tyrosine residue with the smaller alanine residue [45].

One example of creating highly active and specific enzyme is reported with sortase A from Staphylococcus aureus, which catalyzes the transpeptidation of an LPXTG peptide acceptor and a glycine-linked peptide donor. This has proven to be a powerful tool for sitespecific protein modification due to its transpeptidation activity but its high specificity limits its broader utility. Recently, two orthogonal sortase A variants have been developed by applying directed laboratory evolution technique that recognize each of two different substrates, LAXTG and LPXSG, with high activity and specificity. The evolved sortases exhibit changes in specificity up to 
Table 1 Examples of fold improvements in promiscuous functions

\begin{tabular}{|c|c|c|c|c|}
\hline Enzymes & Native function/substrate & $\begin{array}{l}\text { Promiscuous functions/sub- } \\
\text { strate }\end{array}$ & $\begin{array}{l}\text { Improvement by directed } \\
\text { laboratory evolution and/or } \\
\text { rational designing }\end{array}$ & References \\
\hline \multirow[t]{2}{*}{ Mammalian serum paraoxonase } & \multirow[t]{2}{*}{ Lipo-lactonase } & $\begin{array}{l}\text { Phosphotriesterase CMP-Couma- } \\
\text { rine (racemic mixture) }\end{array}$ & 77-fold higher & {$[35]$} \\
\hline & & CMP-Coumarine (sp isomer) & 86,000 -fold & {$[39]$} \\
\hline \multirow{3}{*}{$\begin{array}{l}\text { Phosphotriesterase (PTE) from } \\
\text { bacteria }\end{array}$} & \multirow[t]{3}{*}{ Paraoxon hydrolysis } & Racemic nerve agent VX & 230-fold & \multirow[t]{2}{*}[42]{} \\
\hline & & DEVX & 78-fold & \\
\hline & & Malathion & 5000-fold & {$[43]$} \\
\hline $\begin{array}{l}\text { PLL scaffold (Dr0930) from } \\
\text { Deinococcus radiodurans }\end{array}$ & Lactonase & OP hydrolase & $69,000-$ fold & {$[52]$} \\
\hline $\begin{array}{l}\text { Sortase A from Staphylococcus } \\
\text { aureus }\end{array}$ & Transpeptidation of LPXTG & LAXTG and LPXSG & 51,000 -fold & {$[44]$} \\
\hline $\begin{array}{l}\text { Human glutathione transferase } \\
\text { (GST) M2-2 }\end{array}$ & $\begin{array}{l}\text { 2-cyano-1,3-dimethyl-1-nitroso- } \\
\text { guanidine }\end{array}$ & Azathioprine & 30-fold & {$[53]$} \\
\hline
\end{tabular}

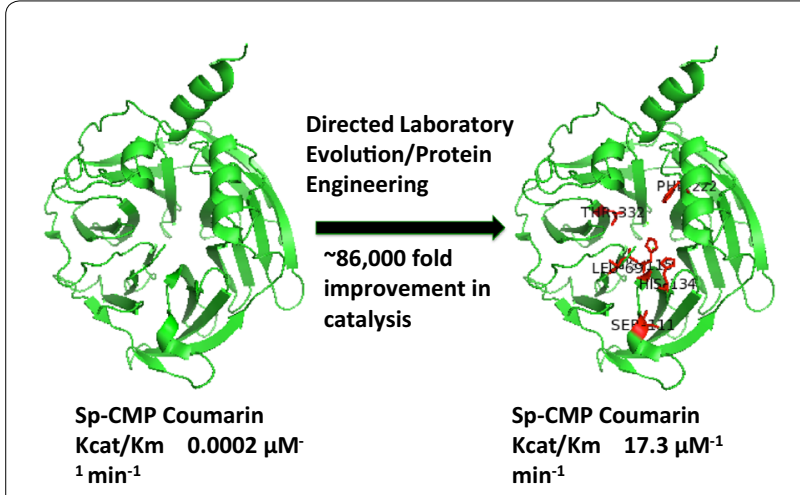

Fig. 3 Improvement in promiscuous function of mammalian serum PON1. Several rounds of mutagenesis and selection by applying directed laboratory evolution and rational protein designing approaches resulted in the PON1 mutant exhibiting 86,000-fold improvement in $\mathrm{Kcat} / \mathrm{Km}$ values for the hydrolysis of stereospecific G-type nerve agent analogue Sp-CMP Coumarin. The selected clone had following mutations as compare to the starting gene-LI69G, S111T, H115W, H134R, F222S and T332S, which are displayed in the figure

51,000 -fold, relative to the starting sortase without much loss of catalytic activity [46].

Lipases are well studied due to high industrial value and applications. Candida antarctica lipase B (CALB) is a well-known for its promiscuous activity which can be utilized for designing new catalysts for important organic reactions [47]. The active site of CALB is similar to that of soluble epoxide hydrolase, which are formed by a nucleophile-histidine-acid catalytic triad and an oxyanion hole similar to $\alpha / \beta$ hydrolases. Recently, a S105D variant of CALB was identified as a new catalyst for epoxide hydrolysis. The hydrolysis of the trans-diphenylpropene oxide is studied in particular and suggested that the mutant
CALB is a good protein scaffold to be used for the biosynthesis of chiral compounds [48]. Similarly, lipase SrLip from Streptomyces rimosus (Q93MW7) revealed lipase, phospholipase, esterase and thioesterase activities [49]. Porcine pancreatic lipase (PPL), one of the best enzymes identified for biocatalytic aldol addition at lower temperature but much accelerated activity at elevated temperature. Recently, a novel peptidase is reported from thermophilic archaea Sulfolobus tokodaii for its catalytic promiscuity of aldol addition, which shows comparable activity as PPL. The catalytic efficiency of this enzyme at $55^{\circ} \mathrm{C}$ adds up to 140 times higher than that of PPL at its optimum physiological temperature. This study is an example, which signifies the importance to identify a new enzyme with catalytic promiscuity and demonstrates the application of novel biocatalyst from thermophile microorganisms [50].

A recent report describes the designing of an enzyme capable of discriminately etherifying the parahydroxyl of coniferyl alcohol in the presence of excess sinapyl alcohol. The designed enzyme mutant has a considerably smaller substrate-binding pocket that forces a clear steric hindrance thus excluding larger lignin precursors. Lignin is derivative of three monolignols, which are polymerized by oxidative reactions. The composition of the monolignol monomers determines the degree of lignin condensation and thus the degradability of plant cell walls. Guaiacyl lignin is considered as the condensed structural unit [50]. The active site of a monolignol 4-O-methyltransferase (MOMT5) was precisely remodeled to create an enzyme that specifically methylates the condensed guaiacyl lignin precursor coniferyl alcohol. They started with the promiscuous engineered enzyme, MOMT5 with mutations T133L, E165I, F175I, F166W and H169F. Together with the mutant information, 
crystal structural information with combinatorial active site saturation mutagenesis were applied and remodeled its substrate binding pocket by the addition of four substitutions, i.e., M26H, S30R, V33S, and T319M [51]. Type I plant nucleases are known to play an important role in apoptotic processes and cell senescence. The first structure of tomato nuclease showed its oligomerization and activity profiles resulted in unexpected promiscuous activity towards phospholipids. Solving the crystal structure of this protein identified possible binding sites for double stranded DNA and other nucleic acids. Essentially, the phospholipase activity of tomato nuclease I significantly broaden the substrate promiscuity of the enzyme, and resulted in the release of diacylglycerol. The diacylglycerol is an important second messenger that can be related to the role of tomato nuclease $I$ in apoptosis [52].

\section{Conclusions}

The above observations support the hypothesis that promiscuous functions are not exceptions but inherent features of proteins in general. However, the mechanisms of exhibiting promiscuity are different in different proteins, enzymes in particular. It can be categorized in three major groups based on the different factors responsible for enzyme promiscuity: (1) active site plasticity of enzymes, (2) substrate ambiguity and (3) cofactor ambiguity. Owing to the weaker promiscuous activity as compare to native activity, it could be a better starting point for the evolution of new function. It also provides an immediate advantage to the gene under selection for a new function. However, the importance of promiscuous functions especially with physiologically irrelevant substrates is yet to be understood. The promiscuous functions can also be utilized as a starting point for the evolution of new proteins in laboratory conditions for biotechnological applications.

\footnotetext{
Acknowledgements

Financial supports from Department of Science and Technology (SERB/F/1424) and South Asian University are gratefully acknowledged.
}

\section{Competing interests}

The author declares that he have no competing interests.

Received: 29 October 2015 Accepted: 19 January 2016

Published online: 02 February 2016

\section{References}

1. Khersonsky O, Tawfik DS (2010) Enzyme promiscuity: mechanistic and evolutionary perspective. Annu Rev Biochem 79:471-505

2. Copley SD (2014) An evolutionary perspective on protein moonlighting. Biochem Soc Trans 42(6):1684-1691
3. Gupta RD, Goldsmith M, Ashani Y, Simo Y, Mullokandov G, Bar H, BenDavid M, Leader H, Margalit R, Silman I, Sussman JL, Tawfik DS (2011) Directed evolution of hydrolases for prevention of G-type nerve agent intoxication. Nat Chem Biol 7(2):120-125

4. Jackson CJ, Foo JL, Tokuriki N, Afriat L, Carr PD, Kim HK, Schenk G, Tawfik DS, Ollis DL (2009) Conformational sampling, catalysis, and evolution of the bacterial phosphotriesterase. Proc Natl Acad Sci USA 106(51):21631-21636

5. Bigley AN, Mabanglo MF, Harvey SP, Raushel FM (2015) Variants of phosphotriesterase for the enhanced detoxification of the chemical warfare agent VR. Biochemistry 54(35):5502-5512

6. Nobeli I, Favia AD, Thornton JM (2009) Protein promiscuity and its implications for biotechnology. Nat Biotechnol 27:157-167

7. Copley SD (2009) Evolution of efficient pathways for degradation of anthropogenic chemicals. Nat Chem Biol 5(8):559-566

8. López-Iglesias M, Gotor-Fernández V (2015) Recent advances in biocatalytic promiscuity: hydrolase-catalyzed reactions for nonconventional transformations. Chem Rec 15(4):743-759

9. Baier F, Tokuriki N (2014) Connectivity between catalytic landscapes of the metallo-ß-lactamase superfamily. J Mol Biol 426(13):2442-2456

10. Parera M, Martinez MA (2014) Strong epistatic interactions within a single protein. Mol Biol Evol 31(6):1546-1553

11. Copley SD (2015) An evolutionary biochemist's perspective on promiscuity. Trends Biochem Sci 40(2):72-78

12. Atkins WM (2015) Biological messiness vs. biological genius: mechanistic aspects and roles of protein promiscuity. J Steroid Biochem Mol Biol 151:3-11

13. Arora B, Mukherjee J, Gupta MN (2014) Enzyme promiscuity: using the dark side of enzyme specificity in white Biotechnology. Sustainable Chemical Processes 2:25

14. Penning TM, Chen M, Jin Y (2015) Promiscuity and diversity in 3-ketosteroid reductases. J Steroid Biochem Mol Biol 151:93-101

15. Miao Y, Rahimi M, Geertsema EM, Poelarends GJ (2015) Recent developments in enzyme promiscuity for carbon-carbon bond-forming reactions. Curr Opin Chem Biol 25:115-123

16. Matange N, Podobnik M, Visweswariah SS (2015) Metallophosphoesterases: structural fidelity with functional promiscuity. Biochem J 467(2):201-216

17. Noda-García L, Juárez-Vázquez AL, Ávila-Arcos MC, Verduzco-Castro EA, Montero-Morán G, Gaytán P, Carrillo-Tripp M, Barona-Gómez F (2015) Insights into the evolution of enzyme substrate promiscuity after the discovery of $(\beta a)$ isomerase evolutionary intermediates from a diverse metagenome. BMC Evol Biol 15:107

18. Huang H, Pandya C, Liu C, Al-Obaidi NF, Wang M, Zheng L, Toews Keating S, Aono M, Love JD, Evans B, Seidel RD, Hillerich BS, Garforth SJ, Almo SC, Dunaway-Mariano PS, Mariano D, Allen KN, Farelli JD (2015) Panoramic view of a superfamily of phosphatases through substrate profiling. Proc Natl Acad Sci USA 112(16):e1974

19. Mashiyama ST, Malabanan MM, Akiva E, Bhosle R, Branch MC, Hillerich B, Jagessar K, Kim J, Patskovsky Y, Seidel RD, Stead M, Toro R, Vetting MW, Almo SC, Armstrong RN, Babbitt PC (2014) Large-scale determination of sequence, structure, and function relationships in cytosolic glutathione transferases across the biosphere. PLoS Biol 12(4):e1001843

20. Pratap S, Katiki M, Gill P, Kumar P, Golemi-Kotra D (2015) Active-site plasticity is essential to carbapenem hydrolysis by OXA-58 Class D $\beta$-lactamase of Acinetobacter baumannii. Antimicrob Agents Chemother 60:75-86

21. Alcolombri U, Elias M, Tawfik DS (2011) Directed evolution of sulfotransferases and paraoxonases by ancestral libraries. J Mol Biol 411(4):837-853

22. Kraus ML, Grimm C, Seibel J (2015) Redesign of the active site of sucrose phosphorylase by a clash induced cascade of loop shifts. Chem Bio Chem. doi:10.1002/cbic.201500514

23. Afriat-Jurnou L, Jackson CJ, Tawfik DS (2012) Reconstructing a missing link in the evolution of a recently diverged phosphotriesterase by active-site loop remodeling. Biochemistry 51(31):6047-6055

24. Yasutake Y, Yao M, Sakai N, Kirita T, Tanaka I (2004) Crystal structure of the Pyrococcus horikoshii isopropylmalate isomerase small subunit provides insight into the dual substrate specificity of the enzyme. J Mol Biol 344:325-333 
25. Sevrioukova IF, Poulos TL (2013) Understanding the mechanism of cytochrome P450 3A4:recent advances and remaining problems. Dalton Trans 42(9):3116-3126

26. Yao J, Guo H, Chaiprasongsuk M, Zhao N, Chen F, Yang X, Guo H (2015) Substrate-assisted catalysis in the reaction catalyzed by salicylic acid binding protein 2 (SABP2), a potential mechanism of substrate discrimination for some promiscuous enzymes. Biochemistry 54(34):5366-5375

27. Baier F, Chen J, Solomonson M, Strynadka NC, Tokuriki N (2015) Distinct metal isoforms underlie promiscuous activity profiles of metalloenzymes. ACS Chem Biol 10(7):1684-1693

28. Marschner A, Klein CD (2015) Metal promiscuity and metal-dependent substrate preferences of Trypanosoma brucei methionine aminopeptidase 1. Biochimie 115:35-43

29. Pordea A (2015) Metal-binding promiscuity in artificial metalloenzyme design. Curr Opin Chem Biol 25:124-132

30. Rivera-Perez C, Nyati P, Noriega FG (2015) A corpora allata farnesyl diphosphate synthase in mosquitoes displaying a metal ion dependent substrate specificity. Insect Biochem Mol Biol 64:44-50

31. Kim Y, Cunningham MA, Mire J, Tesar C, Sacchettini J, Joachimiak A (2013) NDM-1, the ultimate promiscuous enzyme: substrate recognition and catalytic mechanism. FASEB J 27(5):1917-1927

32. Tokuriki N, Tawfik DS (2009) Protein dynamism and evolvability. Science 324:203-207

33. Kaltenbach M, Tokuriki N (2014) Dynamics and constraints of enzyme evolution. J Exp Zool B Mol Dev Evol 322(7):468-487

34. Amitai G, Gupta RD, Tawfik DS (2007) Laten evolutionary potentials under the neutral mutational drift of an enzyme. HFSP J 1(1):67-78

35. Gupta RD, Tawfik DS (2008) Directed enzyme evolution via small and effective neutral drift libraries. Nat Methods 5(11):939-942

36. Miles ZD, Roberts SA, McCarty RM, Bandarian V (2014) Biochemical and structural studies of 6-carboxy-5, 6, 7, 8-tetrahydropterin synthase reveal the molecular basis of catalytic promiscuity within the tunnel-fold superfamily. J Biol Chem 289(34):23641-23652

37. Luo XJ, Kong XD, Zhao J, Chen Q, Zhou J, Xu JH (2014) Switching a newly discovered lactonase into an efficient and thermostable phosphotriesterase by simple double mutations His250lle/lle263Trp. Biotechnol Bioeng 111(10):1920-1930

38. Khanal A, Yu McLoughlin S, Kershner JP, Copley SD (2015) Differential effects of a mutation on the normal and promiscuous activities of orthologs: implications for natural and directed evolution. Mol Biol Evol 32(1):100-108

39. de Visser JA, Krug J (2014) Empirical fitness landscapes and the predictability of evolution. Nat Rev Genet 15(7):480-490

40. Harms MJ, Thornton JW (2013) Evolutionary biochemistry: revealing the historical and physical causes of protein properties. Nat Rev Genet 14(8):559-571

41. Renata H, Wang ZJ, Arnold FH (2015) Expanding the enzyme universe: accessing non-natural reactions by mechanism-guided directed evolution. Angew Chem Int Ed Engl 54(11):3351-3367
42. Colin PY, Kintses B, Gielen F, Miton CM, Fischer G, Mohamed MF, Hyvönen M, Morgavi DP, Janssen DB, Hollfelder F (2015) Ultrahigh-throughput discovery of promiscuous enzymes by picodroplet functional metagenomics. Nat Commun 6:10008

43. Meier MM, Rajendran C, Malisi C, Fox NG, Xu C, Schlee S, Barondeau DP, Höcker B, Sterner R, Raushel FM (2013) Molecular engineering of organophosphate hydrolysis activity from a weak promiscuous lactonase template. J Am Chem Soc 135(31):11670-11677

44. Bigley AN, Xu C, Henderson TJ, Harvey SP, Raushel FM (2013) Enzymatic neutralization of the chemical warfare agent VX: evolution of phosphotriesterase for phosphorothiolate hydrolysis. J Am Chem Soc 135(28):10426-10432

45. Naqvi T, Warden AC, French N, Sugrue E, Carr PD, Jackson CJ, Scott C (2014) A 5000-fold increase in the specificity of a bacterial phosphotriesterase for malathion through combinatorial active site mutagenesis. PLoS One. 9(4):e94177

46. Dorr BM, Ham HO, An C, Chaikof EL, Liu DR (2014) Reprogramming the specificity of sortase enzymes. Proc Natl Acad Sci USA 111(37):13343-13348

47. Sharma UK, Sharma N, Kumar R, Kumar R, Sinha AK (2009) Biocatalytic promiscuity of lipase in chemoselective oxidation of aryl alcohols/acetates: a unique synergism of CAL-B and [hmim] $\mathrm{Br}$ for the metal-free $\mathrm{H}_{2} \mathrm{O}_{2}$ activation. Org Lett 11(21):4846-4848

48. Bordes I, Recatalá J, Świderek K, Moliner V (2015) Is promiscuous CALB a good scaffold for designing new epoxidases? Molecules 20(10):17789-17806

49. Leščić Ašler I, Ivić N, Kovačić F, Schell S, Knorr J, Krauss U, Wilhelm S, Kojić-Prodić B, Jaeger KE (2010) Probing enzyme promiscuity of SGNH hydrolases. Chem Bio Chem 11(15):2158-2167

50. Li R, Perez B, Jian H, Jensen MM, Gao R, Dong M, Glasius M, Guo Z (2015) Characterization and mechanism insight of accelerated catalytic promiscuity of Sulfolobus tokodaii (ST0779) peptidase for aldol addition reaction. Appl Microbiol Biotechnol 99:9625-9634

51. Cai Y, Bhuiya MW, Shanklin J, Liu CJ (2015) Engineering a Monolignol 4-O-methyltransferase with High Selectivity for the Condensed Lignin Precursor Coniferyl Alchohol. J Biol Chem. 290:26715-26724

52. Koval'T, Lipovová P, PodzimekT, Matoušek J, Dušková J, SkálováT, Stěpánková A, Hašek J, Dohnálek J (2013) Plant multifunctional nuclease TBN1 with unexpected phospholipase activity: structural study and reaction-mechanism analysis. Acta Crystallogr D Biol Crystallogr 69(Pt 2):213-226

53. Norrgård MA, Mannervik B (2011) Engineering GST M2-2 for high activity with indene 1,2-oxide and indication of an $\mathrm{H}$-site residue sustaining catalytic promiscuity. J Mol Biol 412(1):111-120

\section{Submit your manuscript to a SpringerOpen ${ }^{\circ}$ journal and benefit from:}

- Convenient online submission

- Rigorous peer review

- Immediate publication on acceptance

- Open access: articles freely available online

- High visibility within the field

- Retaining the copyright to your article

Submit your next manuscript at $>$ springeropen.com 